DOI: https://doi.org/10.24867/06GI01Mijatovic

\title{
ANALIZA SKLADIŠNOG POSLOVANJA I PREDLOG MERA ZA UNAPREĐENJE U KOMPANIJI ,TEHNOPLAST"
}

\section{WAREHOUSE BUSINESS ANALYSIS AND SUGGESTION FOR IMPROVEMENT MEASURES AT ,TEHNOPLAST" COMPANY}

\author{
Ivana Mijatović, Fakultet tehničkih nauka, Novi Sad
}

\section{Oblast - INŽENJERSKI MENADŽMENT}

Kratak sadržaj - U radu je izvršena analiza procesa skladištenja u kompaniji „,Tehnoplast“, analizirani su problemi funkcionisanja skladišta i predložene su mere za unapređenje skladišnog poslovanja.

Ključne reči: Logistika, analiza, zalihe, skladište, mere unapređenja

\begin{abstract}
The work presents storage process analysis at „Tehnoplast“ company, warehouse functioning problems are analyzed and measures are proposed to improve warehouse operations.
\end{abstract}

Keywords: Logistics, analysis, supplies, warehouse, improvement measures

\section{UVOD}

U današnjem poslovnom svetu nemoguće je zamisliti proizvodnu kompaniju koja nema organizavano skladišno poslovanje. Međutim, značajno je imati dobro organizovano skladišno poslovanje kako bi kompanija dobro poslovala i mogla da ispunjava zahteve kupaca.

Pojmovi kao što su skladište i zalihe je nemoguće posmatrati odvojeno. Pronaći i zadržati balans među zalihama predstavlja ozbiljan zadatak i izazov za menadžment kompanije. Postoje dva slučaja. U prvom slučaju kada nema dovoljno zaliha u skladištu, javlja se problem da se proizvodnja mora obustaviti dok ne stignu nove zalihe, što rezultira zastojima i čekanjima, a to nepovoljno utiče na rad preduzeća. U drugom slučaju kada ima više zaliha nego što je potrebno one vremenom propadaju, zauzimaju prostor i u njima je zarobljen kapital. Jasno je da je i ovo opasna situacija po kompaniju.

Naravno treba napomenuti da svaka kompanija treba pomno da prati trendove, koji su u današnjem poslovanju sve više podložni promenama, da bude u koraku sa informacionim tehnologijama, da bude fleksibilna, da koristi medote i tehnike unapređenja kvaliteta i da proaktivno reaguje. Menadžment kompanije treba da bude u stanju da predviđa promene, a celokupna kompanija treba da teži ka tome da bude korak ispred u odnosu na konkurente.

\section{NAPOMENA:}

Ovaj rad proistekao je iz master rada čiji mentor je bio dr Stevan Milisavljević, vanredni profesor.

\section{LOGISTIKA}

\subsection{Definicija logistike}

Logistika kao pojam upotrebljava se u dva značenja:

1. Naučna disciplina - ubrzavanje tokova materijala, povećanja efikasnosti, prostorna i vremenska dinamika procesa reprodukcije; analitičke, statističke, matematičke, empirijske metode i primena veštačke inteligencije, u prvom redu ekspertnih sistema.

2. Poslovna funkcija - skup aktivnosti u organizaciji koje podržavaju izvršavanje njegovog osnovnog zadatka (proizvodnja ili pružanje usluga) i omogućavaju nesmetano odvijanje procesa reprodukcije [1].

Logistika je integracija i upravljanje lancem vrednosti proizvoda od dobavljača do kupca. Uključuje sve aspekte lanca proizvodnje, dizajn, dobavljače, finansiranje, informacije, energiju, transport, distribuciju i prodaju.

Prema Savetu stručnjaka za upravljanje lancem snabdevanja - Council of Supply Chain Management Professionals (ranije Savet za logističko upravljanje - Council of Logistics Management) logistika je proces planiranja, implementacije i kontrole postupaka za efikasan transport i skladištenje roba, uključujući usluge i srodne informacije od mesta proizvodnje do mesta potrošnje, sa svrhom usaglašavanja sa zahtevima kupaca i uključuje ulazno, izlazno, unutrašnje i spoljno kretanje [2].

\subsection{Zadaci logistike}

Zadaci poslovne logistike kao funkcije sastoje se u:

- Snabdevanju radnih mesta sa svime što je potrebno za uspešno izvršenje radnog zadatka.

- Efikasnom korišćenju faktora „,vreme“.

- Primeni logističkih modela, metoda i tehnike rada na rešavanju problema $u$ oblasti snabdevanja.

- Praćenju i analizi podobnosti primenjenih logističkih modela, metoda i tehnika rada.

Obezbeđenju povratnog uticaja primene logističkih modela, metoda i tehnika rada na dalji razvoj logistike kao nauke [3].

Osnovni i najvažniji zadatak logistike jeste da kupac bude zadovoljan. 


\section{ZALIHE}

\subsection{Pojam zaliha i nekurentne zalihe}

Zalihe su takođe i složena ekonomska kategorija koja se javlja u različitim oblicima angažovanih sredstava. Kada bi potrebne količine predmeta rada bile unapred poznate $\mathrm{i}$ precizne, kako količinski, tako i u pogledu momenata ulaska u proces proizvodnje i kada bi dužina vremena nabavke takođe bila unapred poznata, kontinuitet procesa proizvodnje bi mogao da se obezbedi odgovarajućom organizacijom procesa nabavke.

Nekurentne zalihe: Nekurentne zalihe predstvljaju zalihe robe koja iz određenih razloga nije prodata $\mathrm{u}$ zadatom i planiranom roku. Razlozi mogu biti loše predviđanje potražnje, prekomerno naručivanje zbog niske cene, loša procena tržišta itd. Za ovakvom robom jednostavno više nema potreba na tržištu, ali se ona mora negde skladištiti dok se ne napravi plan šta sa njom dalje raditi. Naravno skladištenje nekurentnih zaliha podrazumeva dodatne troškove, a zalihe samim stajanjem u skladištu gube na vrednosti.

Nekurentne zalihe se još nazivaju i „mrtve“ zalihe. Nekonkurentne zalihe su količine zaliha koje prelaze optimalne zalihe. One su iznad optimuma zaliha koji se nalazi između minimalne i maksimalne zalihe $\mathrm{i}$ čini onu količinu zaliha koja uz najniže troškove, odnosno troškove nabavke i troškova držanja zaliha, osigurava nesmetano odvijanje procesa proizvodnje i prodaje. Zbog toga postaju smetnja normalnom radnom procesu, zakrčuju kapacitet proizvodnje i skladišta, povećavaju troškove zaliha, smanjuju obrtaj zaliha i utiču na rentabilnost poslovanja [4].

\subsection{Modeli upravljanja zalihama}

Modeli upravljanja zalihama dele se na:

- Push i

- Pull modele.

Push model (model „guranja“) planira naloge za proizvodnju ili isporuku robe unapred. Proizvođači „guraju“ finalne proizvode kroz distribucione kanale, ka posrednicima i krajnjim korisnicima.

Push modeli su:

1. Ekonomična količina nabavke (EOQ Economic Order Quantity),

2. Planiranje potreba materijala (MRP I - Material Requirements Planing),

3. Planiranje proizvodnih resursa (MRP II Manufakturing Resources Planning) i

4. Planiranje distribucije potreba/zahteva (DRP Distribution Requirements Planning).

Pull modeli su bazirani na proizvodnji ili plasmanu robe, kada su zahtevi krajnjeg korisnika poznati (proizvodi za poznatog kupca). Proizvod se ,povlači“ kroz kanal distribucije po nalogu/zahtevu.

Pull modeli su:

\section{- JIT (Just-In-Time) i}

- Kanban [5].

\section{SKLADIŠTE}

\subsection{Pojam skladišta i skladištenja}

Skladište je posebno opremljena prostorija u kojoj se obavlja prijem, smeštaj, čuvanje, pakovanje, uzorkovanje, sortiranje, obeležavanje, utvrđivanje kvaliteta i izdavanje materijala, poluproizvoda, gotovih proizvoda, ambalaže, sitnog inventara, kao i priprema ovih dobara za otpremu u proizvodne pogone, prodavnice ili kupcima.

Skladišno poslovanje podrazumeva skup poslova koji se odnose na prihvatanje, čuvanje i izdavanje nabavljene ili već proizvedene robe.

Skladištenje robe je faza $\mathrm{u}$ procesu proizvodnje, naravno $\mathrm{u}$ funkciji logistike.

\section{OPŠTI PODACI O KOMPANIJI „TEHNOPLAST“}

Kompanija je osnovana 1968. godine u Zemunu, a premeštena je u Stare Banovce 1972. godine, a 2018. godine su proslavili 50 godina postojanja.

Na površini od $6000 \mathrm{~m} 2$ poslovno magacinskog prostora raspoređene su službe prodaje, nabavke, knjigovodstva administrativne službe kao i dizajnersko-konstruktorski tim, moderna alatnica i proizvodni pogon za brizganje plastike.

Osnovna delatnost kompanije jeste prerada tehničke plastike, a glavni proizvod su spratne table za automatske osigurače.

Budući da postoji kompletan tehnološki ciklus, ova kompanija je u mogućnosti da u odgovarajućem vremenu odgovori na zahteve tražnje kako u proizvodnji postojećih proizvoda, tako i u razvoju potpuno novih proizvoda.

Kompanija izvozi svoje proizvode u više od 30 zemalja sveta, sa konstantnom tendencijom porasta i proširenja. Kompanija 93\% svojih proizvoda izvozi na strana tržišta, dok $7 \%$ prodaje na domaćem tržištu.

\section{SNIMAK STANJA}

$\mathrm{S}$ obzirom da se proizvodi jedan proizvod, proizvodni asortiman kompanije je podeljen u serije, a svaka serija sadrži više tipova.

U katalogu kompanije se umesto naziva spratne table nalazi naziv razvodne kutije, tako da će se u nastavku rada koristiti ovaj drugi naziv iz kataloga, odnosno razvodne kutije.

Razvodne kutije mogu biti:

- Nazidne i

- Ugradne.

Prodajni asortiman:

- Proizvodi serije ALFA - razvodne kutije IP40 Nazidne,

- Proizvodi serije E - razvodne kutije IP40 Ugradne,

- Proizvodi serije D - razvodne kutije IP65 Nazidne, 
- Proizvodi serije C - razvodne kutije IP40 Nazidne i Ugradne,

- Proizvodi serije A - razvodne kutije IP40 Ugradne i razvodne kutije IP30 Nazidne,

- Proizvodi serije F - razvodne kutije IP40 Ugradne,

- IT serija,

- Kombo serija i

- Dodatna oprema - nosači za WiFi ruter, dupla priključnica sa nosačem, bravica sa ključem za razvodne kutije serije $\mathrm{E}$ i $\mathrm{F}$, pregrada sa integrisanom priključnicom, bravica sa ključem za razvodne kutije serije $C$, spojnica za kućište, vertikalni spoj, spojnica za kućište, horizontalni spoj.

Proizvodi serije $\mathrm{C}$ su najprodavaniji proizvodi.

\section{PROBLEMI SKLADIŠNOG POSLOVANJA}

Glavni problem skladišnog poslovanja koji kompanija Tehnoplast ima jeste nedostatak prostora za skladištenje poluproizvoda i gotovih proizvoda.

$\mathrm{S}$ obzirom na velike količine robe koju proizvodi, kompanija ima problem gde i kako pravilno rasporediti robu u skladištu.

Problem je takođe i to što rukovodilac proizvodnje upravlja i skladišnim poslovanjem. Rukovodilac proizvodnje sam ne stiže da na kvalitetan način vrši upravljanje i prooizvodnjom i skladištem, s obziorom na to da je njegova primarna funkcija upravljanje proizvodnjom.

Još jedan problem koji kompanija ima jeste magacin br. 3, u kome se nalazi „sve i svašta“. Uzrok i ovog problema jeste nedostatak prostora za skladištenje, kao i neadekvatno upravljanje skladištem.

Problem kojem je potrebno pokloniti posebnu pažnju jeste problem kašnjenja u isporuci gotovih proizvoda kupcima.

\section{ANALIZA PROBLEMA SKLADIŠNOG POSLOVANJA}

Za potrebe ovog rada i problema funkcionisanja skladišta korišćene su sledeće metode: Ishikawa dijagram i FMEA, koje su objašnjene u nastavku.

Ishikawa dijagram

Isikawa dijagrm predstavlja metodu za detaljnu analizu odnosa između određenog stanja sistema (posledice) i uticajnih veličina koje uslovljavaju pojavu datog stanja (uzroka). On se naziva jos i dijagram uzrok-posledica.

Koraci Ishikawa dijagrama:
1. Definisanje problema.
2. Identifikacija uzroka.
3. Izbor osnovne strukture.
4. Razrada dijagrama.
5. Postupak širenja (grananja).
6. Analiza.

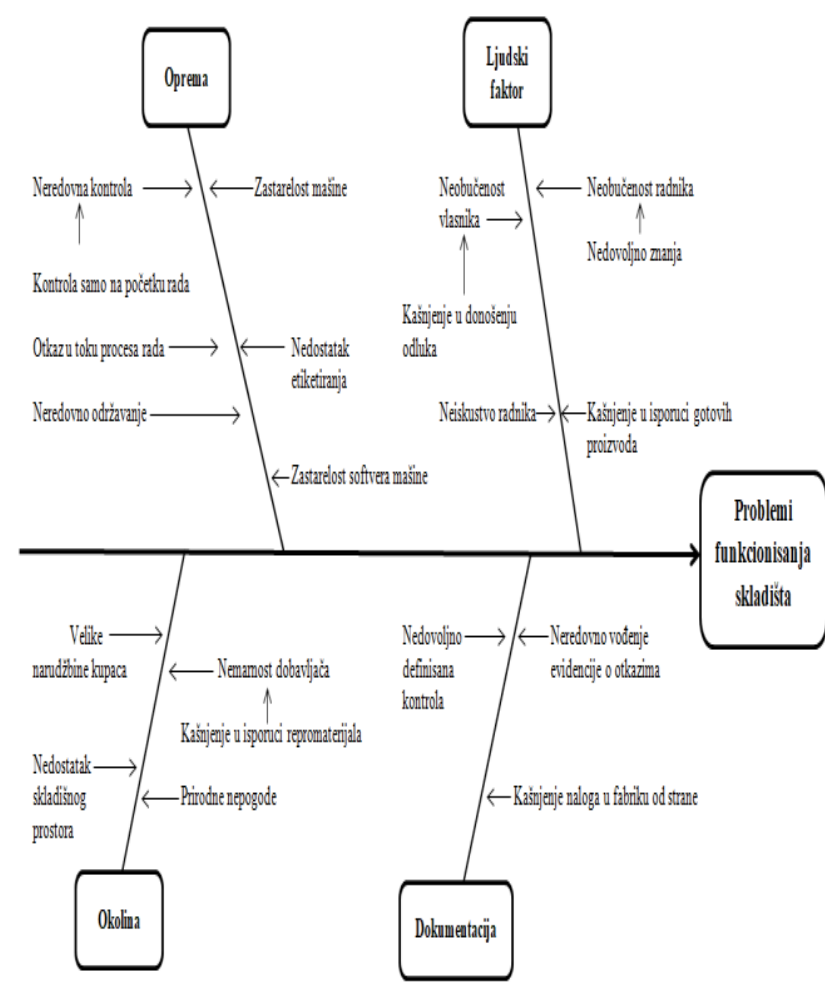

Slika 1. Ishikawa dijagram

\section{FMEA}

Zbog obimnosti FMEA analize, u ovom radu biće objašnjena samo tabela sa konačnim rezultatima u kojoj su predložene akcije za otklanjanje uzroka problema, odgovornosti i rokovi završetka akcija. Tri glavna uzroka koja dovode do problema funkcionisanja skladišta su: nedostatak etiketiranja, kašnjenje $u$ isporuci gotovih proizvoda kupcima i nedostatak skladišnog prostora.

Dakle, za nedostatak etiketiranja preporučena akcija je uvođenje Print\&Apply sistema etiketiranja. Za sprovođenje ove akcije odgovorni su vlasnik i zaposleni, a rok za uvođenje preporučene akcije je nedelju dana.

Što se tiče kašnjenja $u$ isporuci gotovih proizvoda kupcima, preporučena akcija je uvođenje knjige o otkazima. Za sprovođenje ove akcije odgovorni su radnici, a rok za uvođenje preporučene akcije je nedelju dana.

Nedostatak skladišnog prostora bi se rešio tako što bi preporučena akcija bila izgradnja dodatnog magacina. Za sprovođenje ove akcije odgovorni su vlasnik i građevinska kompanija, a rok za uvođenje preporučene akcije je šest meseci.

\section{PREDLOZI ZA UNAPREĐENJE SKLADIŠNOG POSLOVANJA}

Predlozi za unapređenje skladišnog poslovanja su:

- Izradnja dodatnog magacina,

- Uvođenje Print\&Apply sistema etiketiranja i

- Kontrolna knjiga o otkazima.

\subsection{Izgradnja dodatog magacina}

S obzirom da kompanija poseduje sopstveno zemljište koje nije iskorišćeno, a nalazi se na istom mestu gde se 
nalaze i sedište i skladišta kompanije, kompanija ne bi imala dodatne troškove $u$ vidu kupovine novog zemljišta $i$ trošenja vremena na uknjižavanje istog i samim tim je $u$ prednosti što se tog dela tiče. Ovaj dodatni magacin bi bio korišćen u svrhu skladištenja isključivo gotovih proizvoda koji čekaju da budu utovareni u prevozna sredstva, naravno $\mathrm{s}$ poštovanjem datuma $\mathrm{i}$ rokova isporuke kupcima. Magacin bi bio izgrđen u obliku fudbalskih balona (balon hala), sa pripremom terena kao da će biti betonska hala (kao što su urađeni magacin br. 1, 2 i 3) i sa visokopaletnim drive in regalima unutar magacina.

Treba napomenuti da se i problem magacina br. 3 mora rešiti, a to bi se postiglo tako što bi se već postojeći paletni regali koji se nalaze u magacinu br. 4 prebacili u magacin br. 3 i na taj način magacin br. 3 bi bio još jedno dodatno skladište i poluproizvoda i gotovih proizvoda, a stvari koje nisu potrebne i koje se više ne koriste $\mathrm{u}$ poslovanju bi trebalo spremiti i odložiti na kontejnere.

\subsection{Uvođenje Print\&Apply sistema etiketiranja}

Print\&Apply sistemi M-serije za štampanje i automatsko apliciranje etiketa osiguravaju ispunjenje svih industrijskih zahteva u pogledu sledljivosti, identifikacije i obeležavanja kako proizvoda tako i transportnih pakovanja i paleta. M-serija je modularna, što znači da ispunjava sve najčešće zahteve, ali može da se prilagodi i vrlo specifičnim zahtevima. Ovakvu vrstu etiketiranja bi izvršila kompanija Elmed iz Novog Sada. Ova kompanija je koncentrisana na isporučivanje integrisanih rešenja za kodiranje, etiketiranje kao i kontrolu gotovog proizvoda.

Ona sadrži najefikasniji štampač, glavu za štampanje kao i potrošni materijal za proizvodnu liniju.

\subsection{Kontrolna knjiga za održavanje opreme}

U ovoj knjizi vode se svi podaci o strukturi i tehnologijama održavanja opreme od datuma prijema u organizaciju. Sastavni delovi Kontrolne knjige za održavanje opreme su: mašinska karta radne sposobnosti, karton o redovnim i vanrednim pregledima opreme, karton o remontu opreme i karton otkaza opreme.

Mašinska karta radne sposobnosti. Ovaj deo Kontrolne knjige sadrži osnovne tehničke karakteristike mašine: proizvođač mašine, tip i oznaka mašine, fabrički broj, godina proizvodnje, atest stručne ustanove kao i ostale tehničke karakteristike.

Karton o redovnim i vanrednim pregledima opreme. Radi preventivnog delovanja sprovodi se periodično vizuelno pregledanje opreme. Za svaku mašinu određuje se period redovnih pregleda. Pregled vrše radnici koji su za to određeni, a kontrolu vrše poslovođe održavanja [6].

Karton o remontu opreme. Ovaj deo Kontrolne knjige održavanja se otvara pri remontu opreme i u njega se unose: početak i kraj remonta, vrsta popravke, izvršilac radova, naziv dela koji je zamenjen i potpis poslovođe održavanja.

Karta otkaza predstavlja bitan dokument u vezi sa održavanjem mašina i opreme. Karta otkaza prikazuje za svako sredstvo precizno vreme nastanka kvara i popravke, trajanje zastoja, tekst prijave kvara i opis popravke.

\section{ZAKLJUČAK}

Najbolja iskorišćenost skladišnog prostora jeste kad postoje visokopaletni regali, jer se na taj način postiže potpuna iskorišćenost prostora, na način koji omogućava da se na jedno paletno mesto može složiti u visinu više paletnih regala.

Važno je shvatiti koliko je bitno da se na kvalitetan $\mathrm{i}$ adekvatan način upravlja skladišnim poslovanjem, i da bi tu funkciju trebalo da rade obrazovani i stručni ljudi koji su specijalizovani za tu oblast. Na taj način se smanjuju troškovi poslovanja koje izaziva činjenica da upravljanje u skladištima vrši lice koje nije obučeno za tu funkciju u kompaniji. Manji troškovi znače i veća finansijska sredstva koja kompanija može koristiti za sopstvene potrebe a s ciljem njenog proširenja, odnosno koja ne spadaju u zarobljeni kapital.

Dakle, skladišta su vrlo osetljiva kategorija svake proizvodne kompanije i bez njih nije moguće ostvariti poslovanje u proizvodnim delatnostima, ali ukoliko se uoči na vreme njihov značaj i angažuju kvalitetni ljudi koji će rukovoditi njihovim poslovanjem, to će imati veoma pozitivan uticaj na svaku kompaniju.

\section{LITERATURA}

[1] „Razvoj i pojam Logistike“, Univerzitet Sinergija

[2] Supply chain management, terms and glossary, http://arquivo.pt/wayback/20160524204314/https://csc mp.org/sites/default/files/user_uploads/resources/dow nloads/glossary-2013.pdf (pristupljeno u avgustu 2019.)

[3] Logistika preduzeća, http://studenti.rs/skripte/logistika-preduzeca/ (pristupljeno u avgustu 2019.)

[4] Krpan Lj., Maršanić, R., Jedvaj V. Upravljanje zalihama materijalnih dobara i skladišno poslovanje $u$ logističkoj industriji

[5] Logistika - Organizacija i menadžment“, dr. Dragutin SD Stanivuković, Novi Sad, 2003.

[6] Kontrolna knjiga za održavanje opreme, https://studenti.rs/download/?f=42635 (pristupljeno u avgustu 2019.)

\section{Kratka biografija:}

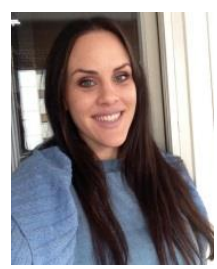

Ivana Mijatović rođena je u Novom Sadu 1994. godine. Master rad na Fakultetu tehničkih nauka iz oblasti Inženjerski menadžment - Menadžment kvaliteta i logistike odbranila je 2019.godine. Kontakt: ivana.mijatovic1994@gmail.com 